\title{
Editorial Ockham's broom: A new series
}

\author{
Miranda Robertson
}

Although it is increasingly difficult to gauge what people can be expected to know, it is probably safe to assume that most readers are familiar with Ockham's razor - roughly, the principle whereby gratuitous suppositions are shaved from the interpretation of facts - enunciated by a Franciscan monk, William of Ockham, in the fourteenth century. Ockham's broom is a somewhat more recent conceit, attributable to Sydney Brenner, and embodies the principle whereby inconvenient facts are swept under the carpet in the interests of a clear interpretation of a messy reality. (Or, some - possibly including Sydney Brenner might say, in order to generate a publishable paper.)

In due course, the edge of the carpet must be lifted and the untidy reality confronted, and in this issue of Journal of Biology we are launching an occasional series of Opinions in which contributors inspect the sweepings and discuss their implications. The inaugural contribution, published today, is from Bruce Mayer and colleagues [1] on signaling ensembles. They argue that the kind of helpful cartoon we are accustomed to leaning on in order to understand the mechanics of signaling pathways - and that they deploy themselves in their Figure 1 - is grossly misleading (as graphically illustrated in their Figure 2), and we need (and are beginning to have) better ways both to investigate and to analyze the reality of signaling dynamics. It can be argued that the willingness of investigators to come to terms with the hitherto unexplained is a measure of the maturity of the field, and indeed it seems that this is a carpet whose time has come, and Mayer et al. are not alone in peering under it - see for example [2].

To elaborate that point briefly - While Ockham's razor clearly has an established important and honourable place in the philosophy and practice of science, there is, despite its somewhat pejorative connotations, an honourable place for the broom as well. Biology, as many have pointed out, is untidy and accidental, and it is arguably unlikely that all the facts can be accounted for early in the investigation of any given biological phenomenon. For example, if only Charles Darwin had swept under the carpet the variation he faithfully recorded in the ratios of inherited traits in his primulas, as Mendel did with his peas, we might be talking of Darwinian inheritance and not Mendelian (see [3]). Clearly, though, it takes some special sophistication, or intuition, to judge what to ignore.

I should like to be able to end by trailing the next broom in our series, but it hasn't quite arrived at the time of writing, and all editors know what a mistake it is to count unhatched chickens. So I will stop before I mix another metaphor.

\section{Miranda Robertson, Editor}

editorial@jbiol.com

\section{References}

1. Mayer BJM, Blinov ML, Loew LM: Molecular machines or pleiomorphic ensembles: signaling complexes revisited. $J$ Biol 2009, 8:81.

2. Gibson TJ: Cell regulation: determined to signal discrete cooperation. Trends Biochem Sci 2009, 34:471-482.

3. Howard JC: Why didn't Darwin discover Mendel's laws? J Biol 2009, 8:15.

Published: 16 October 2009

doi:10.1186/jbiol187

(C) 2009 BioMed Central Ltd 